\title{
HUBUNGAN INSENTIF DAN KESELAMATAN DAN KESEHATAN KERJA (K3)DENGAN KINERJAKARYAWAN PADA PT. PETRO ANTARNUSA KOTA BENGKULU
}

\author{
Nia Indriasari, Tri Hadi Purnomo \\ Program Studi Manajemen Fakultas Ekonomi Universitas Dehasen Bengkulu \\ Indriasarinia@yahoo.com
}

\begin{abstract}
ABSTRAK
Nia Indriasari, Tri Hadi Purnomo ; Penelitian ini bertujuan untuk mengetahui hubungan insentif dan Keselamatan dan Kesehatan Kerja (K3)dengan kinerja karyawan pada PT. Petro Antar Nusa Kota Bengkulu. Sampel dalam penelitian ini sebanyak 32 orang sopir dan kondektur pada PT. Petro Antar Nusa Kota Bengkulu. Metode pengumpulan data menggunakan kuesioner dan metode analisis yang digunakan adalah korelasi spearman rank dan uj hipotesis dengan uji t. Hasil penelitian menjelaskan bahwa insentif memiliki hubungan yang kuat dengan kinerja karyawan pada PT. Petro Antar Nusa Kota Bengkulu dengan nilai korelasi sebesar 0,778. Hal ini menggambarkan bahwa insentif yang diberikan oleh PT. Petro Antar Nusa Kota Bengkulu dapat menunjang dalam mingkatkan kinerja, karena dengan adanya insentif akan menimbulkan semangat kerja yang tinggi dan karyawan berusaha untuk selalu berprestasi. Hal ini diperkuat dengan hasil pengujian hipotesis yaitu thitung lebih besar dari tabel $(6,780>1,697)$. Dengan demikian hasil uji hipotesis adalah $\mathrm{H}_{01}$ ditolak dan $\mathrm{H}_{\mathrm{a} 1}$ diterima. Artinya Insentif mempunyai hubungan yang signifikan dengan kinerja karyawan pada PT. Petro Antar Nusa Kota Bengkulu.Keselamatan dan kesehatan kerja memiliki hubungan yang kuat dengan kinerja karyawan pada PT. Petro Antar Nusa Kota Bengkulu dengan nilai korelasi sebesar 0,644. Hal ini menggambarkan bahwa dengan adanya perhatian perusahaan terhadap kesehatan dan keselamatan kerja dari para karyawan pada PT. Petro Antar Nusa Kota Bengkulu maka akan meningkatkan kinerja dari para karyawan. Hal ini diperkuat dengan hasil pengujian hipotesis yaitu thitung lebih besar dari tabel $(4,611>1,697)$. Dengan demikian hasil uji hipotesis adalah $\mathrm{H}_{02}$ ditolak dan $\mathrm{H}_{\mathrm{a}}$ diterima. Artinya Keselamatan dan Kesehatan Kerja (K3)mempunyai hubungan yang signifikan dengan kinerja karyawan pada PT. Petro Antar Nusa Kota Bengkulu
\end{abstract}

\section{ABSTRACT}

Nia Indriasari, Tri Hadi Purnomo;. This study aims to determine the relationship of incentives and Occupational Safety and Health (K3) with employee performance at PT. Petro Antar Nusa Bengkulu City. The sample in this research are 32 driver and conductor at PT. Petro Antar Nusa City Bengkulu. Data collection method using questioner and analysis method used is spearman rank correlation and hypothesis test with $t$ test. Incentives have a very strong relationship with employee performance at PT. Petro Antar Nusa Bengkulu City with correlation value of 0.778. This illustrates that the incentives provided by PT. Petro Antar Nusa Bengkulu City can support in improving the performance, because with the incentives will lead to high morale and employees strive to always excel. This is reinforced by hypothesis test result that is tcount bigger than ttable $(6,780>1,697)$. Thus the result of hypothesis test is H01 rejected and Ha1 accepted. This means that incentives have a significant relationship with employee performance at PT. Petro Antar Nusa Bengkulu City. Occupational safety and health has a strong relationship with employee performance at PT. Petro Antar Nusa City Bengkulu with correlation value of 0.644. This illustrates that with the company's attention to the health and safety of employees of PT. Petro Antar Nusa Bengkulu City will improve the performance of the employees. This is reinforced by the result of hypothesis testing that is tcount is bigger than ttable (4,611> 1,697). Thus the result of hypothesis test is H02 rejected and Ha2 accepted. This means that Safety and Health (K3) has a significant relationship with the performance of employees at PT. Petro Antar Nusa Bengkulu City.

Key Words: Incentives, Occupational Safety and Health (K3), Performance

\section{LATAR BELAKANG}

Sumber daya manusia memegang peranan penting bagi keberhasilan suatu organisasi, karena sumber daya manusia merupakan aset hidup yang perlu dipelihara dan dikembangkan.Oleh karena itu,sumber daya manusia harus mendapatkan perhatian yang khusus dari perusahaan.

Kinerja dapat diartikan sebagai suatu hasil dan usaha seseorang yang dicapai dengan adanya kemampuan dan perbuatan dalam situasi tertentu (Siagian, 2012:244). Kinerja merupakan perilaku nyata yang ditampilkan setiap orang sebagai prestasi kerja yang dihasilkan oleh karyawan sesuai dengan 
perannya dalam organisasi. Peningkatan kinerja dapat meningkatkan hasil kerja seorang karyawan, sehingga tujuan suatu organisasi akan dapat dicapai dengan adanya tingkat kinerja karyawan yang tinggi. Kinerja dapat dipengaruhi oleh beberapa faktor diantaranya yaitu insentif dan Keselamatan dan Kesehatan Kerja (K3). Insentif memiliki hubungan yang sangat erat dengan kinerja, karena dengan adanya pemberian insentif dari perusahaan maka akan menimbulkan motivasi dari para karyawan untuk meningkatkan kinerjanya. Selain itu Keselamatan dan Kesehatan Kerja (K3) juga mampu meningkatkan kinerja karena dengan adanya jaminan kesehatan dan keselamatan yang diberikan perusahaan maka karyawan akan lebih bersemangat dalam bekerja dengan sendirina kinerja akan meningkat.

PT. Petro Antar Nusa Kota Bengkulu merupakan perusahaan yang menjadi agen resmi dari minyak solar industri yang digunakan untuk industri. Solar industri akan disalurkan ke pabrik-pabrik yang membutuhkan solar tersebut, untuk pendistribusian solar tersebut maka para sopir dan kondektur akan mengantarkannya sampai ke pabrik yang memesan solar industri. Untuk peningkatan kinerja sopir dan kondektur PT. Petro Antar Nusa Kota Bengkulu menjamin keselamatan dan kesehatan kerja para sopir dan kondektur dengan cara memberikan asuransi kecelakaan dan asuransi kesehatan. Meskipun perusahaan telah memberikan jaminan kesehatan dan keselamatan kerja kepada para sopir dan kondektur, tetapi masih terjadi permasalahan karena pembayaran asuransi setiap bulannya masih dipotong dari gaji sopir dan kondektur. Hal inilah yang menjadi permasalahan bagi para sopir dan kondektur, mereka menginginkan agar semua asuransi tersebut dibayarkan oleh perusahaan tanpa harus memotong gaji mereka perbulan.

Sedangkan jika dilihat dari insentif, PT. Petro Antar Nusa Kota Bengkulu memberikan insentif kepada sopir dan kondektur dalam bentuk bonus, pemberian bonus akan diserahkan bersamaan dengan gaji. Bonus yang diberikan berdasarkan banyaknya hasil penjualan yang dicapai. Tetapi permasalahan yang dirasakan oleh sopir dan kondektur, belum adanya penjelasan secara transparan tentang penetapan jumlah bonus yang diterima oleh sopir dan jumlah insentif yang diterima oleh kondektur.

\section{LANDASAN TEORI}

\section{Manajemen Sumber Daya Manusia}

Manajemen Sumber Daya Manusia (MSDM) merupakan bidang strategis dari organisasi. Manajemen sumber daya manusia harus dipandang sebagai perluasan dari pandangan tradisional untuk mengelola orang secara efektif dan untuk itu membutuhkan pengetahuan tentang perilaku manusia dan kemampuan mengelolanya.

\section{Insentif}

Insentif sebagai sarana motivasi yang mendorong para karyawan untuk bekerja dengan kemampuan yang optimal, yang dimaksudkan sebagai pendapatan ekstra di luar gaji atau upah yang telah di tentukan. Pemberian insentif dimaksudkan agar dapat memenuhi kebutuhan para karyawan dan keluarga mereka. Istilah sistem insentif pada umumnya digunakan untuk menggambarkan rencana rencana pembayaran upah yang dikaitkan secara langsung atau tidak langsung dengan berbagai standar kinerja karyawan atau profitabilitas organisasi.

Hasibuan (2010:117) mengemukakan bahwa "Insentif adalah tambahan balas jasa yang diberikan kepada karyawan tertentu yang prestasinya di atas prestasi standar. Insentif ini merupakan alat yang di pergunakan pendukung prinsip adil dalam pemberian kompensasi". Insentif merupakan motivator yang positif bagi para karyawan untuk meningkatkan gairah kerja, kreatifitas dan pengembangan dirinya menuju tenaga yang profesional.

\section{Keselamatan dan Kesehatan Kerja (K3)}

Dalam berinteraksi antara manusia dengan peralatan kerja pada saat kegiatan perusahaan dilakukan sering kali terjadi kecelakaan. Baik yang ditimbulkan oleh pekerjaan itu sendiri maupun lingkungan kerja. Oleh karena itu adanya jaminan keselamatan dan kesehatan kerja merupakan kewajiban yang harus dilaksanakan oleh setiap perusahaan kepada para karyawannya. Suma'mur (2008:1)menerangkan bahwa keselamatan kerja adalah keselamatan yang bertalian dengan mesin, pesawat, alat kerja, bahan dan proses pengolahannya, landasan tempat kerja dan lingkungannya serta cara-cara melakukan pekerjaan. Keselamtan kerja diartikan sebagai suatu pemikiran atau upaya untuk menjamin keutuhan dan kesempurnaan baik jasmaniah maupun rohaniah tenaga kerja pada khususnya dan manusia pada umumnya serta hasil karya dan budayanya.

\section{Kinerja}

Suatu organisasi, baik itu pemerintah maupun swasta, selalu digerakan oleh sekelompok orang yang berperan aktif untuk mencapai tujuan yang ingin dicapai dari organisasi tersebut. Tujuan organisasi 
tentunya tidak akan tercapai jika kinerja anggota atau karyawannya tidak maksimal.

Menurut Mangkunegara (2011:67), kinerja merupakan hasil kerja secara kualitas dan kuantitas yang dicapai oleh seseorang dalam melaksanakan fungsinya sesuai dengan tanggungjawab yang diberikan kepadanya. Tidak jauh berbeda, Siagian(2012:227) mendefinisikan kinerja sebagai suatu keseluruhan kemampuan seseorang untuk bekerja sedemikian rupa sehingga mencapai tujuan kerja secara optimal dan berbagai sasaran yang telah diciptakan dengan pengorbanan yang secara rasio lebih kecil dibandingkan dengan hasil yang dicapai.

\section{KERANGKA ANALISIS}

Insentif $\left(\mathrm{X}_{1}\right)$ :

a. Besarnya insentif

b. Peningkatan insentif

c. Ketepatan dan kelancaran insentif

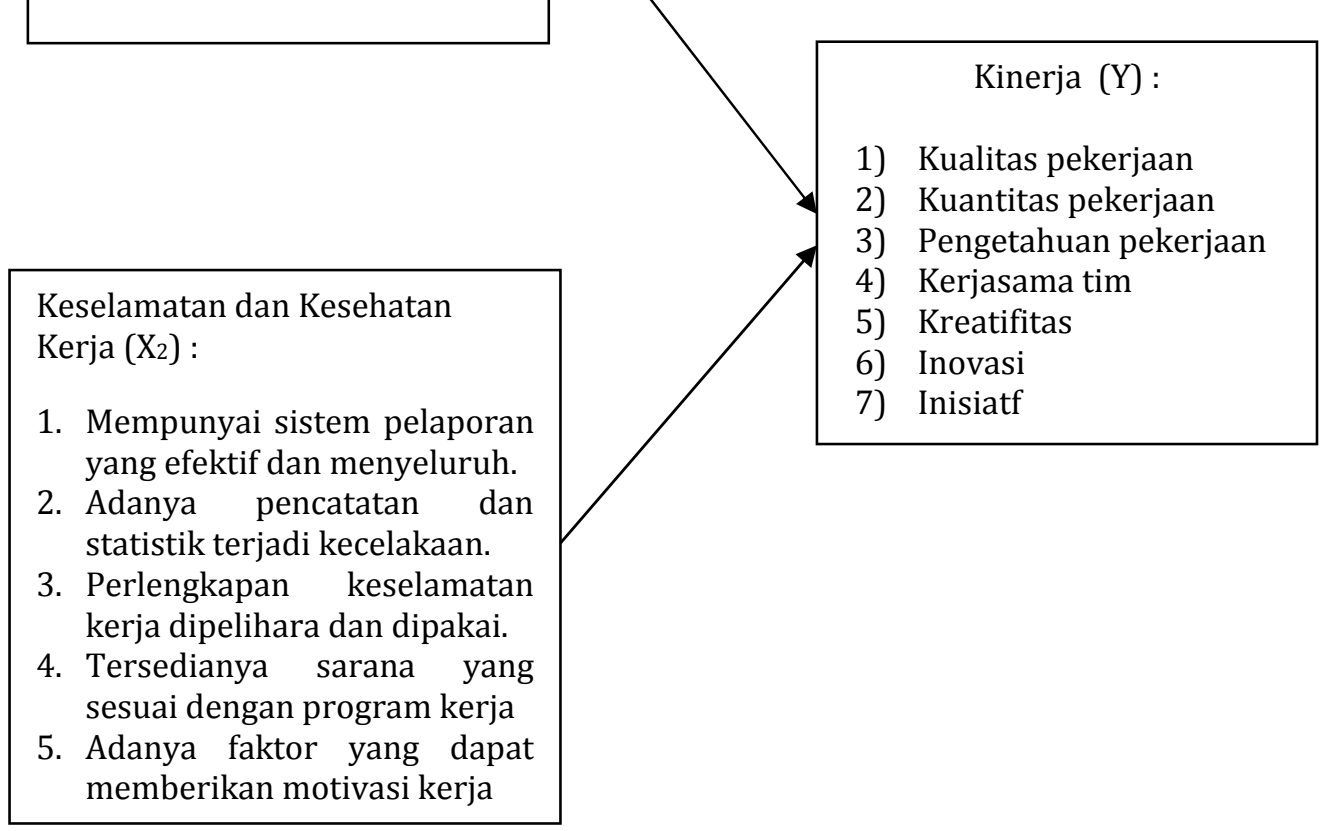

Gambar 1. Kerangka Analisis

\section{METODOLOGI}

\section{Jenis Penelitian dan Metode pengumpulan data}

Penelitian ini termasuk jenis penelitian korelasional. Menurut Sugiyono (2013:67) penelitian korelasional adalah suatu penelitian untuk mengetahui hubungan dan tingkat hubungan antara dua variabel atau lebih tanpa ada upaya untuk mempengaruhi variabel tersebut sehingga tidak terdapat manipulasi variabel. Dalam hal ini penelitian dilakukan untuk :

a. Mengetahui hubungan antara variabel insentif dengan kinerja karyawan pada PT. Petro Antar Nusa kota Bengkulu khususnya sopir dan kondektur.

b. Mengetahui hubungan antara variabel Kesehatan dan Keselamatan Kerja (K3) dengan Kinerja karyawan pada PT. Petro Antar Nusa kota Bengkulu khususnya sopir dan kondektur.

Metode pengumpulan data dimaksudkan untuk memperoleh informasi yang relevan, akurat dan reliabel. Metode pengumpulan data yang di gunakan adalah :

a. Kuesioner

Kuesioner merupakan teknik pengumpulan data yang dilakukan dengan cara memberi seperangkat pertanyaan atau pernyataan tertulis kepada responden untuk dijawabnya (Sugiyono, 2013:142). Data yang diperoleh dalam penelitian ini didapatkan langsung dari pengisian kuesioner (angket) yang ditujukan kepada responden.

b. Dokumentasi

Menurut Sugiyono (2013:240) metode dokumentasi merupakan catatan peristiwa yang sudah berlalu. Dokumen bisa berbentuk tulisan, gambar, atau karya-karya monumental dari seorang. Dokumen yang 
berbentuk tulisan misalnya catatan harian, sejarah kehidupan (life histories), cerita, biografi, peraturan, kebijakan. Metode ini digunakan untuk memperoleh gambaran tentang tempat penelitian seperti sejarah perusahaan dan struktur organisasi.

\section{Metode Analisis}

Metode analisis yang digunakan dalam penelitian ini adalah menggunakan Korelasi Rank Spearman dan uji hipotesis sebagai berikut :

a. Korelasi RankSpearman

Menurut Sugiyono (2013:245) dalam korelasi rank spearman sumber data untuk kedua variabel yang akan dikonversikan dapat berasal dari sumber yang tidak sama, jenis data yang dik orelasikan adalah data ordinal, serta data dari kedua variabel tidak harus membentuk distribusi normal. Jadi korelasi rank spearman adalah bekerja dengan data ordinal atau berjenjang atau rangking, dan bebas distribusi. Adapun rumus korelasi rank spearman adalah :

$$
\rho=1-\frac{6 \sum b x^{2}}{n\left(n^{2}-1\right)}
$$

Sumber : Sugiyono, 2013:184

b. Uji Hipotesis

Uji Hipotesis untuk mengetahui tingkat signifikansi dari korelasi, maka penulis menggunakan statistik uji t dengan rumus sebagai berikut :

$$
t_{\text {hitung }}=r \sqrt{\frac{n-2}{1-r^{2}}}
$$

Agar hasil perhitungan koefisien korelasi dapat diketahui signifikan atau tidak signifikan maka hasil perhitungan dari statistik uji $t$ ( $t$ hitung) tersebut selanjutnya dibandingkan dengan tabel. Tingkat signifikannya yaitu $5 \%(\alpha=0,05)$ dengan uji satu pihak dan derajat kebebasannya (dk $=n-2)$, artinya jika hipotesis nol ditolak dengan taraf kepercayaan $95 \%$, maka kemungkinan bahwa hasil dari penarikan kesimpulan mempunyai kebenaran $95 \%$ dan hal ini menunjukan adanya hubungan (korelasi) yang meyakinkan (signifikan) antara dua variabel tersebut.

\section{HASIL PENELITIAN DAN PEMBAHASAN \\ Analisa Korelasi Rank Spearman}

Untuk mengetahui hubungan antara insentif dan kesehatan dan keselamatan kerja (K3), maka dilakukan analisis menggunakan analisis rank spearman.

a. Hubungan InsentifDengan Kinerja Sopir dan kondektur

Hubungan insentifdengan kinerja sopir dan kondekturPT. Petro Antar Nusa Kota Bengkulumemiliki korelasi yang kuat karena angka 0,778pada tabel 2 interprestasi koefesien korelasi pada range 0,60 0,799 . Hal ini menunjukkan bahwa terdapat korelasi yang kuat antara insentifdengan kinerja sopir dan kondekturPT. Petro Antar Nusa Kota Bengkulu. Artinya semakin tinggi insentifmaka akan semakin tinggi pula tingkatkinerja sopir dan kondekturPT. Petro Antar Nusa Kota Bengkulu.

b. Hubungan Keselamatan dan Kesehatan Kerja (K3) Dengan Kinerja Sopir dan kondektur

Keselamatan dan Kesehatan Kerja (K3) dengan kinerja sopir dan kondekturPT. Petro Antar Nusa Kota Bengkulumemiliki korelasi yang kuat karena angka 0,644pada tabel 2 interprestasi koefesien korelasi pada range $0,60-0,799$. Hal ini menunjukkan bahwa terdapat korelasi yang kuat antara keselamatan dan kesehatan kerja (K3) dengan kinerja sopir dan kondekturPT. Petro Antar Nusa Kota Bengkulu. Artinya semakin tinggi perhatian perusahaan terhadap keselamatan dan kesehatan kerjamaka akan semakin tinggi pula tingkatkinerja sopir dan kondekturPT. Petro Antar Nusa Kota Bengkulu.

\section{Uji Hipotesis}

a. Uji Hipotesis Hubungan Insentif Dengan Kinerja

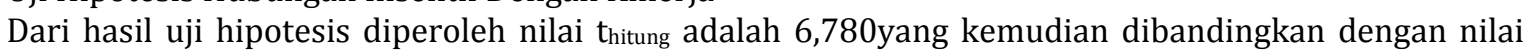
$t_{\text {tabel }}$ dengan level of signifikan ditetapkan 95\% dengan perhitungan satu arah dan $\mathrm{dk}=\mathrm{n}-2=32-2=30$, maka diketahui nilai tabel sebesar 1,697.

Hasil uji hipotesis diketahui bahwa thitung lebih besar dari tabel $(6,780>1,697)$. Dengan demikian hasil uji hipotesis adalah $\mathrm{H}_{01}$ ditolak dan $\mathrm{H}_{\mathrm{a} 1}$ diterima. Artinya Insentif mempunyai hubungan yang signifikan dengan kinerja sopir dan kondektur pada PT. Petro Antar Nusa Kota Bengkulu

b. Uji Hipotesis Hubungan Keselamatan dan Kesehatan Kerja (K3) Dengan Kinerja Sopir dan kondektur 
Dari hasil uji hipotesis diperoleh nilai thitung adalah 4,611 yang kemudian dibandingkan dengan nilai $t_{\text {tabel }}$ dengan level of signifikan ditetapkan $95 \%$ dengan perhitungan satu arah dan $\mathrm{dk}=\mathrm{n}-2=32-2=30$, maka diketahui nilai tabel sebesar 1,697.

Hasil uji hipotesis diketahui bahwa thitung lebih besar dari tabel $(4,611>1,697)$. Dengan demikian hasil uji hipotesis adalah $\mathrm{H}_{02}$ ditolak dan $\mathrm{H}_{\mathrm{a} 2}$ diterima. Artinya Keselamatan dan Kesehatan Kerja (K3)mempunyai hubungan yang signifikan dengan kinerja sopir dan kondektur pada PT. Petro Antar Nusa Kota Bengkulu

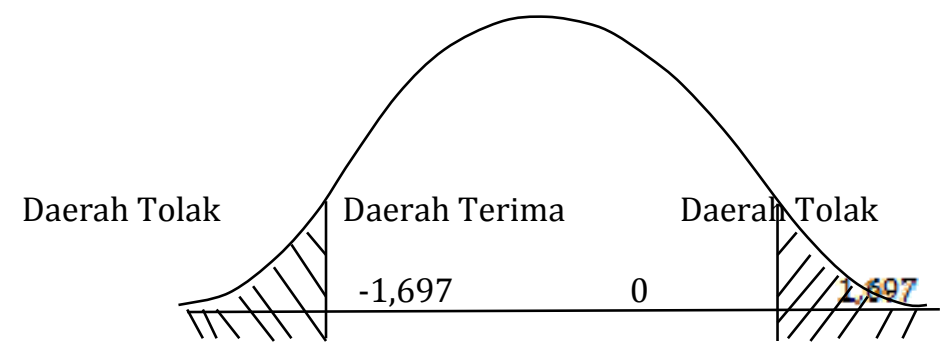

Gambar 2. Daerah penerimaan dan penolakan $\mathrm{H}_{\mathrm{o}}$

\section{Hubungan Insentif Dengan Kinerja Sopir dan kondektur PT. Petro Antar Nusa Kota Bengkulu}

Berdasarkan hasil penelitian dapat diketahui bahwa insentifmemiliki hubungan yang kuat dengan kinerja sopir dan kondektur pada PT. Petro Antar Nusa Kota Bengkulu dengan nilai korelasi sebesar 0,778. Artinya semakin meningkatinsentifmaka akan semakin tinggi pula tingkat kinerja sopir dan kondekturPT. Petro Antar Nusa Kota Bengkulu. Hal ini diperkuat dengan hasil pengujian hipotesis yaitu thitung lebih besar dari tabel $(6,780>1,697)$. Dengan demikian hasil uji hipotesis adalah $\mathrm{H}_{01}$ ditolak dan $\mathrm{H}_{\mathrm{a}}$ diterima. Artinya Insentif mempunyai hubungan yang signifikan dengan kinerja sopir dan kondektur pada PT. Petro Antar Nusa Kota Bengkulu.

Hasil penelitian ini sejalan dengan pendapat yang disampaikan oleh Hasibuan (2010:117) mengemukakan bahwa Insentif adalah tambahan balas jasa yang diberikan kepada karyawan tertentu yang prestasinya di atas prestasi standar. Insentif ini merupakan alat yang di pergunakan pendukung prinsip adil dalam pemberian kompensasi. Insentif merupakan motivator yang positif bagi para sopir dan kondektur untuk meningkatkan gairah kerja, kreatifitas dan pengembangan dirinya menuju tenaga yang profesional.

Insentif yang diberikan oleh perusahaan kepada sopir dan kondekturPT. Petro Antar Nusa Kota Bengkulu terlihat dari adanya pemberian bonus atau insentif bagi sopir dan kondektur yang telah memberikan prestasi tinggi terhadap perusahaan. Insentif pada setiap sopir dan kondektur tidaklah sama besar, karena insentif yang diberikan berdasarkanya besarnya prestasi yang diberikan oleh sopir dan kondektur kepada perusahaan.

Pada PT. Petro Antar Nusa Kota Bengkulu insentif diberikan setiap bulan bersamaan dengan penerimaan gaji, pemberian insentif akan diserahkan lansung oleh bagian keuangan kepada sopir dan kondektur. Perhitungan besarnya insentif berdasarkan prestasi-presati yang telah dicapai oleh sopir dan kondektur.

\section{Hubungan Keselamatan dan Kesehatan Kerja (K3)Dengan Kinerja Sopir dan kondektur PT. Petro Antar Nusa Kota Bengkulu}

Berdasarkan hasil pengujian analisis korelasi rank spearman dan uji hipotesis maka dapat dijelaskan bahwa keselamatan dan kesehatan kerja memiliki hubungan yang kuat dengan kinerja sopir dan kondekturpada PT. Petro Antar Nusa Kota Bengkuludengan nilai korelasi sebesar 0,644. Artinya semakin tinggi perhatian perusahaan terhadap keselamatan dan kesehatan kerja maka akan semakin meningkatkan kinerjasopir dan kondekturPT. Petro Antar Nusa Kota Bengkulu. Hal ini diperkuat dengan hasil pengujian hipotesis yaitu $t_{\text {hitung }}$ lebih besar dari tabel $(4,611>1,697)$. Dengan demikian hasil uji hipotesis adalah $\mathrm{H}_{02}$ ditolak dan $\mathrm{H}_{\mathrm{a} 2}$ diterima. Artinya Keselamatan dan Kesehatan Kerja (K3)mempunyai hubungan yang signifikan dengan kinerja sopir dan kondektur pada PT. Petro Antar Nusa Kota Bengkulu.

Hubungan yang kuat antara keselamatan dan kesehatan kerjadengan kinerjasopir dan kondektursesuai dengan pendapat yang disampaikan oleh Mangkunegara (2011:163) bahwa keselamatan dan kesehatan kerja adalah suatu pemikiran dan upaya untuk menjamin keutuhan dan kesempurnaan baik jasmaniah maupun rohaniah tenaga kerja pada khususnya, dan manusia pada umumnya.Keselamatan dan kesehatan kerja merupakan suatu faktor yang penting dalam terlaksananya kegiatan organisasi. Setiap sopir dan kondekturakan bekerja secara maksimal apabila terdapat jaminan terhadap keselamatan dan kesehatan kerja sopir dan kondektur tersebut dalam bekerja. 
Pada PT. Petro Antar Nusa Kota Bengkulu Keselamatan dan Kesehatan Kerja (K3)diberikan dalam bentuk jaminan kesehatan berupa BPJS yang dibayarkan setiap bulan oleh kantor, selain itu PT. Petro Antar Nusa Kota Bengkulu juga akan menanggung biaya pengobatan yang tidak termasuk dalam tanggungan BPJS dengan cara memberikan kuitansi pembelian obat kepada PT. Petro Antar Nusa Kota Bengkulu dan selanjutnya perusahaan akan memberikan ganti rugi atas biaya tersebut.

\section{KESIMPULAN}

1. Insentif memiliki hubungan yang kuat dengan kinerja karyawan pada PT. Petro Antar Nusa Kota Bengkulu dengan nilai korelasi sebesar 0,778. Hal ini menggambarkan bahwa insentif yang diberikan oleh PT. Petro Antar Nusa Kota Bengkulu dapat menunjang dalam mingkatkan kinerja, karena dengan adanya insentif akan menimbulkan semangat kerja yang tinggi dan karyawan berusaha untuk selalu berprestasi. Hal ini diperkuat dengan hasil pengujian hipotesis yaitu $t_{\text {hitung }}$ lebih besar dari tabel $(6,780$ $>1$,697). Dengan demikian hasil uji hipotesis adalah $\mathrm{H}_{01}$ ditolak dan $\mathrm{H}_{\mathrm{a} 1}$ diterima. Artinya Insentif mempunyai hubungan yang signifikan dengan kinerja karyawan pada PT. Petro Antar Nusa Kota Bengkulu.

2. Keselamatan dan kesehatan kerja memiliki hubungan yang kuat dengan kinerja karyawan pada PT. Petro Antar Nusa Kota Bengkulu dengan nilai korelasi sebesar 0,644. Hal ini menggambarkan bahwa dengan adanya perhatian perusahaan terhadap kesehatan dan keselamatan kerja dari para karyawan pada PT. Petro Antar Nusa Kota Bengkulu maka akan meningkatkan kinerja dari para karyawan. Hal ini diperkuat dengan hasil pengujian hipotesis yaitu thitung lebih besar dari tabel $(4,611>1,697)$. Dengan demikian hasil uji hipotesis adalah $\mathrm{H}_{02}$ ditolak dan $\mathrm{H}_{\mathrm{a} 2}$ diterima. Artinya Keselamatan dan Kesehatan Kerja (K3)mempunyai hubungan yang signifikan dengan kinerja karyawan pada PT. Petro Antar Nusa Kota Bengkulu

\section{SARAN}

1. Diharapkan kepada Kepala PT. Petro Antar Nusa Kota Bengkuluuntuk menambah program keselamatan dan kesehatan kerja para sopir dan kondekturnya, karena tingkat pekerjaan yang dilakukan memiliki resiko yang tinggi seperti memberikan asuransi kecelakaan.

2. Diharapkan kepada sopir dan kondektur PT. Petro Antar Nusa Kota Bengkulu untuk lebih memperhatikan insentif yang diberikan kepada sopir dan kondektur, karena insentif dapat meningkatkan semangat kerja sopir dan kondektur

\section{Daftar Pustaka}

Budiono S. 2006. Bunga Rampai Hiperkes dan Keselamatan Kerja : Higiene Perusahaan, Kesehatan Kerja dan Keselamatan Kerja. Semarang :Undip

Farosta, Raditya, 2015, Hubungan Keselamatan dan Kesehatan Kerja (K3) Dengan Prestasi Kerja Karyawan Pada Surat Kabar Harian Radar Bengkulu, Skripsi, Universitas Dehasen Bengkulu

Fathoni, Abdurrahmat, 2006, ManajemenSumberDayaManusia, Bandung :RinekaCipta

Handoko, T. Hani. 2008. Manajemen. Edisi Kedua, Cetakan Ketiga belas. Yogyakarta : BPFE

Hariandja, Efendi. 2009. Manajemen Sumber Daya Manusia :Pengadaan, Pengembangan, Pengkompensasian, dan Peningkatan . Jakarta :Grasindo

Hasibuan, Malayu. 2010. Manajemen Sumber Daya Manusia. Cetakan Kesembilan. Jakarta : PT BumiAksara.

Mangkunegra, Prabu, Anwar. 2011. Manajemen Sumber Daya Manusia Perusahaan. Bandung : PT RemajaRosdakarya

Moenir. 2012. Manajemen Pelayanan Umum di Indonesia, Jakarta :PT. BumiAksara

Panggabean, Mutiara S. 2008. Manajemen Sumber Daya Manusia. Jakarta :Ghalia Indonesia

Prawirosentono, Suryadi. 2008. Kebijakan Kinerja Karyawan. Yogyakarta:BPFE.

Rivai, Veithzal dan Deddy. Mulyadi. 2013. Kepemimpinan dan Perilaku Organisasi. Edisi Ketiga. Jakarta :Rajagrafindo Persada

Siagian, S.P. 2012. Teoridan Praktek Kepemimpinan. Jakarta: Rineka Cipta

Sofyandi, Herman. 2008. Manajemen Sumber Daya Manusia. , Yogyakarta: Graha Ilmu

Sucipto, Cecep Dani, 2014, Keselamatan dan Kesehatan Kerja, Yogyakarta, GoyengPublising

Sugiyono. 2013. Metode Penelitian Kunatitatif Kualitatif dan R\&D. Cetakan Ke-18 .Bandung Alfabeta.

Sulistiyani, Ambar, Teguh dan Rosidah. 2009. Manajemen Sumber Daya Manusia. Yogyakarta :Graha Ilmu

Suma'mur, 2008. Higene Perusahaan dan Kesehatan Kerja. Gunung Agung, Jakarta.

Sutrisno, Edy. 2009. Manajemen Sumber Daya Manusia. Edisi pertama. Cetakan pertama. Penerbit: Jakarta, Kencana Pranada Media Group 